\title{
Researches on the Way Cloud Media Fuse with Intelligent City
}

\author{
Xu Zhiqiang ${ }^{1, a,{ }^{*}}$, Shan Chongkai ${ }^{1, b},{ }^{2}$ Zou Yamei ${ }^{2, c}$, Li Haidong $^{1, d}$ \\ ${ }^{1}$ School of Sichuan College of Media and Communications, Chengdu 611745, China \\ ${ }^{2}$ Chengdu Aeronautic Polytechnic, Chengdu 610000, China. \\ a1920281000@qq.com, b463601665@qq.com, '53718935@qq.com, d409247922@qq.com
}

\begin{abstract}
Keywords: Cloud media; cloud computing; mega data; intelligent city; endless interaction.
\end{abstract}
\begin{abstract}
With the prosperous development of the next generation Internet technology and the rapid popularization of intelligent ends, cloud media will shift from "one cloud end, multi-screen" to "user-centered" "endless interaction", becoming the next transformation of Internet and serving the world more extensively. Aiming at making the intelligent city construction more humanized, this paper narrates the basic features, platform construction, communication trend of cloud media, and discusses the positioning, fusing and innovation of cloud media in TV, mobile phone, medical treatment and emergency management.
\end{abstract}

\section{Introduction}

Cloud media, the summary of all media in the age of cloud computation, is the fusion of highly fragmentary traditional media and gathers, sorts and releases a variety of information required by the society, and distributes information to people in need after intelligent processing, accordingly making it a newly-rising media serving the society more efficiently with the features of widely gathering, releasing and sharing of information.

Intelligent city, sourced from the concept of "Smart Planet" put forward by IBM[1], is to sense, collect, process relevant information on city operation and to further radiate to all aspects of the society relying on information technologies of Internet of Things, next generation Internet technology and cloud computation, including intelligent response to various demands relating to medical treatment, transportation, education, people's livelihood and social security etc. Intelligent city is the specific embodiment of new-type urbanization, and sustainable development is the construction goal of intelligent city and the concrete action responding to Premier Li Keqiang's view of "Internet + " proposed in Government Work Report during two sessions. A new and more extensive economic development momentum will be formed. This paper analyzes the specific application of cloud media in all aspects of intelligent city, including organic organization and digital processing of various information, resources and media, and offering more user-friendly and convenient service and communication interface to people, enterprises and society. The way how cloud media fuse with intelligent city is also discussed here.

\section{Cloud media}

\section{(1)Basic features of cloud media}

With the rapid development of Internet technology, media fragmentation is growing increasingly obvious. In a sense, a human is a media itself. Information can be communicated through many different medias, and interactive communication has been the main expression means. The key of cloud media is to tightly combine SaaS, PaaS and IaaS together, and the key problem to be resolved is the inter-operation of intelligent media and shifting concepts to practical services centered by people[2].

\section{(2)Platform construction of cloud media}

The technical architecture of cloud media is similar to cloud computing, which consists of three parts: application layer, service level and system layer. The overall architecture of cloud media is presented in Figure 1. 


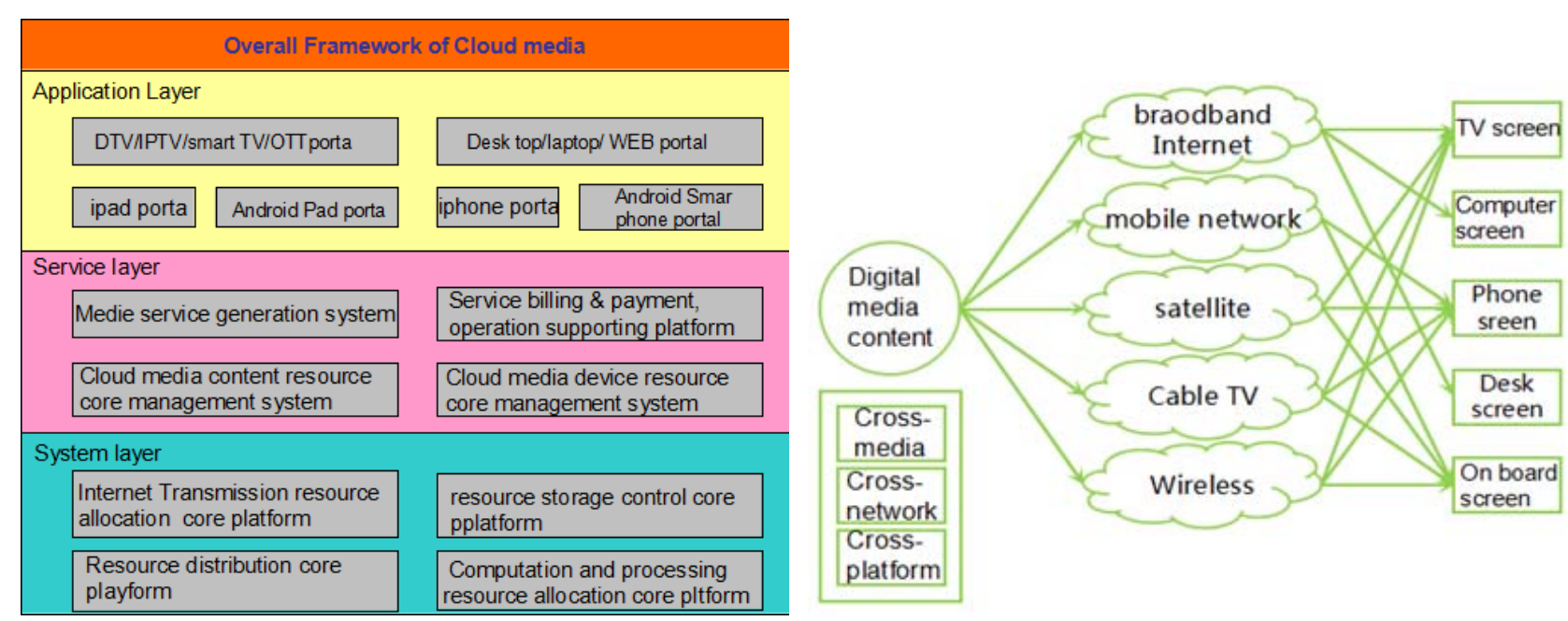

Figure 1. overall technical framework of cloud media

Figure 2. cloud media Multi-network, multi-screen communication trends

(1) Software-as-a-Service (SaaS)

It provides mature service and media resources, actualizes media information, multi-screen interaction and operational multi-screen expansion[3] ,mainly include Smart TV portal modules, OTT portal module, IPTV module, smart mobile phone portal module and so on.

\section{(2) platform-as-a-service (PaaS)}

It provides media content service and resource management, enabling users to access to the content and response.It mainly consists of a business management and BMP module, a customer and administrator module, a MCDN (Media Content Management) and a cloud service support module.

\section{(3) Infrastructure-as-a-service (IaaS)}

It is a base platform providing supports to media service and actualizing management of network transmission and computing capacity.It mainly consists of data storage modules, Internet resource transmission and control modules, resource consolidation, processing and distribution control (3)Cloud media communication trend

Advances in technology have greatly changed users from supply and demand dimensions, while the popularization of mobile devices and $3 \mathrm{G} / 4 \mathrm{G}$ network allows people to be on-line at any time. Through cloud media, more detailed information and data service can be provided, which will offer great convenience to user experience, powerful storage and computation capability to users, ensure acquisition of best content experience on different ends, analysis user preferences and demands, and finally actualize "endless interaction" from "one cloud end multi-screen" to "user centered" "endless interaction"[4]. Based on this, the two major user groups of TV audiences and new media users can be accessed. Cloud end-based big data analysis and Context Awareness end are interconnected, achieving "cross-end, time, space, application, industry and domain" integration (see figure 2) and actualizing personalized demand and service, intelligent service and natural man-machine interaction.

In the future, cloud media is not man-man interaction, but more like man-object, man-system, system-object, system-system interaction and connection. This will also be the next revolution of Internet that is fully focusing on information economy. This is the mainstream economic mode in the post-modern world, and group intelligence will be generated among the experienced Internet users and will in return enhance people's ability of awareness, understanding and management of the world at an exponential rate.

\section{Innovative exploration of fusion development}

Technology, platform, business mode and application of cloud media are changing rapidly and will change people's work, life, communication, education and medical treatment completely. In the future, TV channels will no longer exist, and users will not use remote control anymore. TV screen 
will be the interaction platform between users and media center, a video tool, family entertainment center, social relationship control ends and so on that may meet various needs of users. Cloud media will change the operation mode with the application of new technology, and will reinforce the fusion with data application, Internet, and other devices. Digital technology endows cloud media with various imaginations.

\section{(1) Fusion of cloud media TV into urban construction}

Cloud media TV is the third generation digital TV adapting to the Triple Play Mode after one-way digital TV and interaction TV. By the end of TV screen, it integrates the four media of TV, broadcast, newspaper and Internet, providing video, correspondence and Internet services. After the diversified and specialized setting of channels, it also offers users with channels supporting timeshift, pushing effective information all day in all dimensions. While entertainment services are provided to the public, value-added service platform can be built to server the public for resolving problems relating to personal financing, family life and social donation and other problems by one key. In this way it is then expected to reach the shift from "watching TV" to "using TV". Cloud media TV can be connected to the intelligent libraries of different countries, provinces, cities and universities, enabling people to realize the dream of watching thousands of books without walking out of their house [5]. For example, Taibei built an intelligent library through the way of cloud media. Cloud media TV platform technology framework is shown in Figure 3.

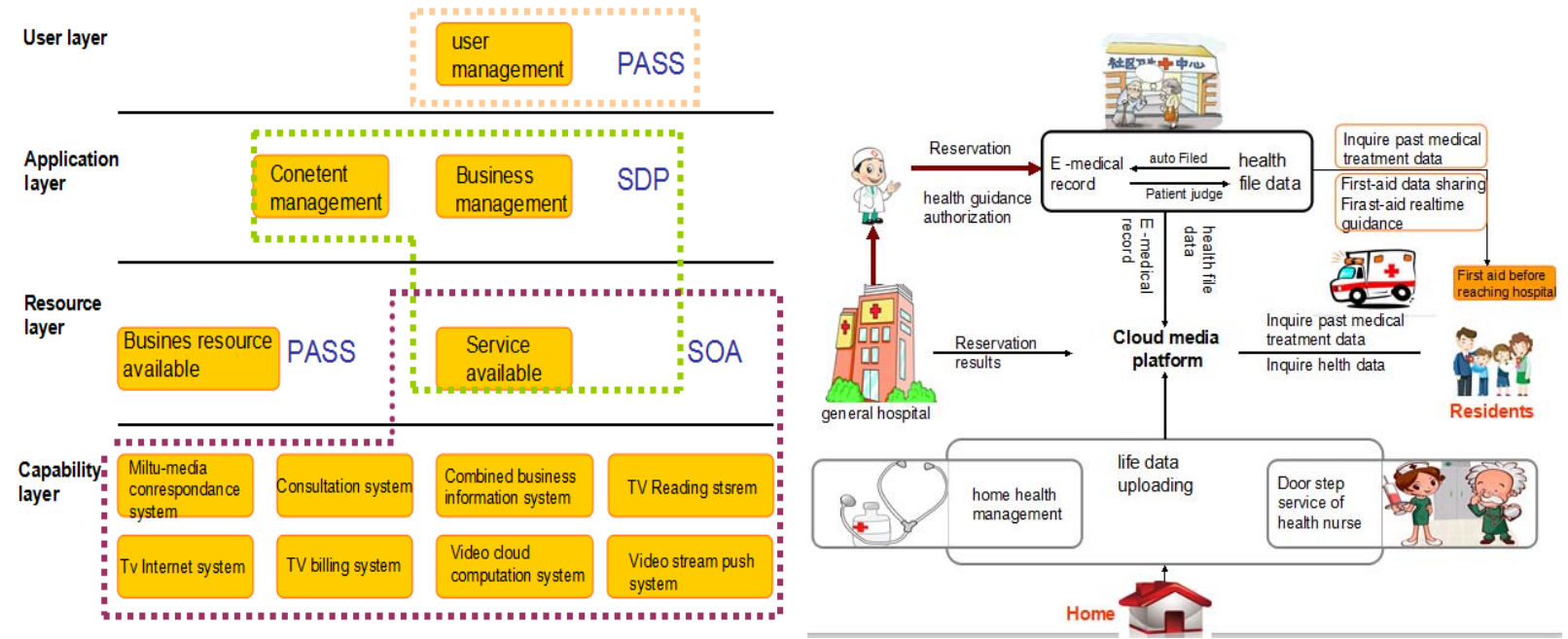

Figure 3. Cloud media TV platform technology framework

Figure 4. Cloud media and intelligent medical treatment

\section{(2)Fusion of cloud media mobile phone with intelligent city}

Cloud Media Phone server will be connected with the data center of intelligent cities, through the phone information and data about the weather, life, economy, education and so on can be pushed to the public. If users want to gain more information, then they can collect and communicate information in order to acquire the qualification and level of information acquisition. In this way, each user, like a journalist, can collect and communicate whatever happens around on a real-time base, so the social information will be more active. Finally through gathering and verifying the information released at the user ends, the final information released will be more reliable. Mobile phones are becoming the interaction interface between man and objects (such as intelligent hardware, home supplies, man accessories). Intelligent mobile phone can be hardly changed in function or concept if it is just considered as a phone. Therefore, under the driving of cloud media, mobile phone will change from "functional devices" to "intelligent devices" that will bring more user-friendly and convenient service means and communication interface.

\section{(3)Fusion of cloud media with intelligent medical treatment}

In the module of intelligent medical treatment, availability and sharing of cloud resources will connect all hospitals on line, and a unified service platform will be built which make a summary of experts' data. operation and diagnosis time, patients' medical records, medical treatment devices and drug information relying on the powerful data storage center. By using the cloud media platform, 
patients will be more convenient in registration and reservation of treatment time, hospital, experts. When patients need to transfer to other hospitals, cloud media will enable information sharing, that is, the medical record of the previous hospital will be kept and visited by the next hospital directly, helping patients to save the expenses of doing examinations again. the fusion of cloud media and the Internet of things will generate a lot of intelligent devices. For example, lonely elderly can wear information record bracelets that can record their vital signs, and health assessment can be performed timely through cloud media platform, convenient for communities and hospitals to handle emergencies. Cloud media and intelligent medical treatment frameworkare presented in figure 4.

\section{(4) Fusion of cloud media with city emergency}

Public security construction has been the foundation of urban economic development and community building. Through cloud computation, the magic computing and storage capacity of big data can record the monitoring data, weather changing data, crustal movement data, water resources and electricity data, immigration quarantine data, dangerous goods like the toxic, flammable and explosive objects, firearms, ammunition etc., all of which can be gathered in the data center. After accurate date sorting and analysis, the on-site video, sound and files can be sent back to the emergency management platform, and the danger can be classified immediately based on the situation. Then relevant departments can deploy their strategies through cloud media. Once any accidents happened, city emergency system will be launched and loud media ends and public platform will give notices to the public in the fastest way, and emergency broadcasting ends will cover all corners. People can be evacuated efficiently, accordingly causalities and losses can be reduced. Cloud media and urban emergency framework are shown in figure 5.

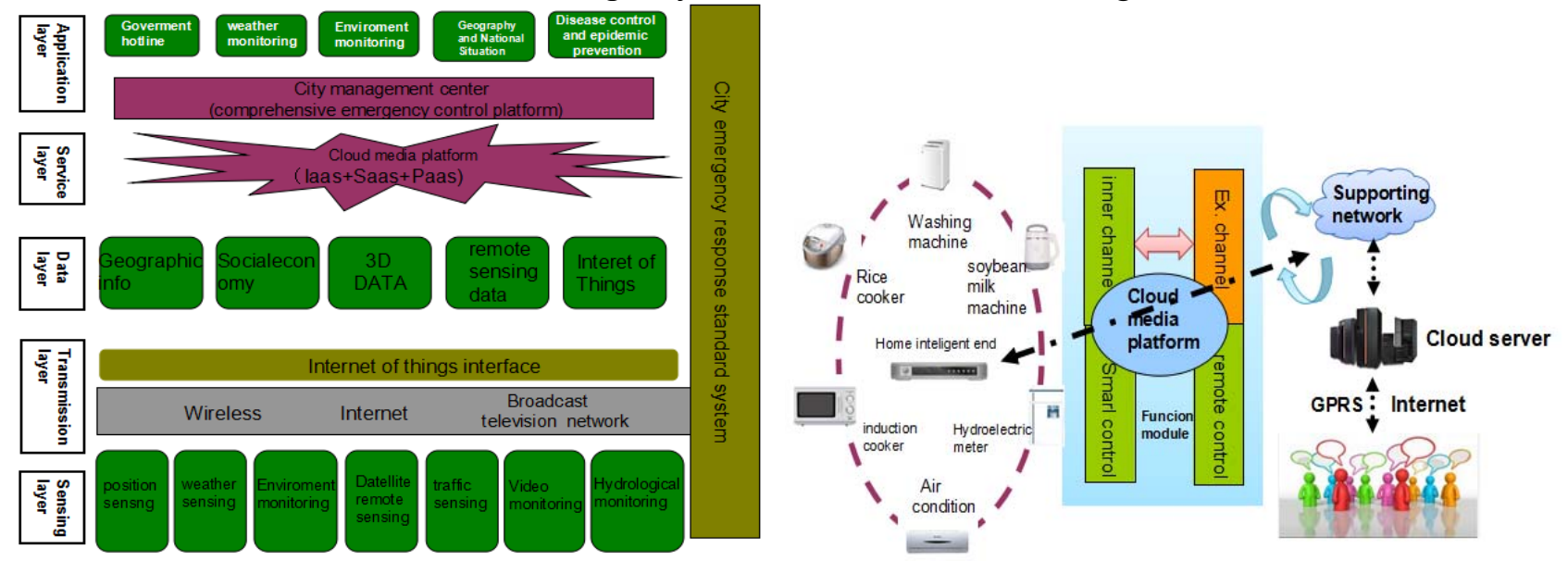

figure 5. Cloud media and urban emergency framework

Figure 6. Cloud media and intelligent family framework

(5)Fusion of cloud media with intelligent family

The core of intelligent family includes broadband connection, Internet devices, community gateway, carrier services and billing mode[6]. The combination of cloud media and Internet of things can well serve an intelligent family where the utility data are gathered and monitored and the user safety is guaranteed through management and control of platform and sensing devices. When utility fee and property management fee need to be paid, cloud service will make payment automatically. Cloud system can record people's daily life depending on its powerful storage function, while room temperature, air quality, weather information and security information will be sent to the cloud end, and cloud media platform will make reaction accordingly to synchronize the information to the mobile end. According to people's living habits and requirements on living quality, relevant parameters will be regulated automatically. It is able to know about the situation of the family anytime and anywhere, and handle the emergencies reasonably and timely. Besides this, it also supports remote education, household expenses and Internet interaction. Cloud media and intelligent family framework is shown in figure 6. 


\section{(6)Fusion of cloud media with food safety}

Food safety is the concrete employment of intelligent city. Intelligent city emphasizes people-oriented, insists to the principles of health, greenness and safety. To apply the advantages of cloud to food security is significant to people's well-being. It can provide a platform that uses cloud storage technology to record the processing, production and sales of raw materials to the government, enterprises (food manufacturers, raw materials suppliers, vendors, etc. ), and individuals, and consumers can know about the food information through the ends anytime and anywhere; enterprises can receive consumers' feedback and reviews through the platform, and then make improvement, whereas government can reinforce supervision on enterprises, accept consumers' reports and thereby filtrate safety monitoring and information connection to all links of food security. Through cloud media platform, the triple relationship among government, enterprises and individuals can be coordinated, convenient for food tracking, consumption feedback and so on. The application of cloud media technology is like building a food security platform supervised by all users, accordingly guaranteeing citizens' basic interest.

\section{Conclusion}

In the age of cloud media, human beings pay more attention to the balanced communication and harmonious relation construction among human, device and content. Internet has been the extension of the whole value chain of traditional media, so traditional media should make constant innovation while interacting with Internet in order to find the main direction and logic of new value creation under the condition of "internet $+",{ }^{[8]}$ eventually dynamic management of resources can be achieved.

Through understanding of cloud media and intelligent city, the way how cloud media fuse with intelligent city is discovered. It is proposed that cloud media has incomparable advantages including media resource integration, real-time update and massive resource sharing. Its fusion with intelligent city is close related to the benefits of the nation, society, enterprises and individuals. With constant technological reform and enhancement, cloud media will offer users with brand new media cloud service including powerful searching functions, massive resources,[7] multi-screen and intelligent interaction. While enhancing user experience, it also serves the construction of intelligent city.

\section{Acknowledgments}

This work was partially supported by A Project Supported by Scientific Research Fund of SiChuan Provincial Education Department (No.14ZA0317、No.15ZA0352) and Sichuan Provincial Department of Education Science and technology achievements transformation of major cultivation project (16CZ0041).

\section{References}

[1]IBM Cloud Computation Center Hipods.“Intelligent Planet”-IBM Cloud Computation 2.0 (R).IBM China, 2009: 1-7.

[2]Cao Shansheng, Cloud Media Business Support Platform in the Context of Triple Play [J]. TV technology, November 17, 2012.

[3]Ji Hai, Li Cong, Cao Sansheng. APPLICAITON MODE AND Technical Framework of Cloud Media Platform [J].Word Broadband Internet Vol 9.42-43.

[4]Wang Wenbin. From One Cloud Multi Screen to Multi Screen Interaction, _-Exploration and Practices of TV Station with Internet [J].TV Research.2014 No.10.

[5]Geng Naifan, Cloud Media TB as Foundational Support Platform, Building Intelligent City and Creating Happy Wellbeing [J]. Journal of China Broadcast TV; Vol 52012. 
[6]Xu Zhiqiang, Research and Modeling of Triple Play Based Intelligent Family Service System[J]. China Communication Media Technology. Vol. 092013.

[7]Chen Kang, Zheng Weimin, Cloud COmputation, Ssyetm Case and Research Status [J]. Journal of Software.2009.20(5):1337-1348. 